\title{
Corpo e docência: a dança circular como promotora do desenvolvimento da consciência
}

\author{
Paula Costa de Andrada \\ Faat Faculdades Atibaia - Atibaia - SP \\ Vera Lúcia Trevisan de Souza \\ Pontifícia Universidade Católica de Campinas - Campinas - SP
}

\begin{abstract}
Resumo
Este trabalho apresenta os resultados de uma pesquisa de doutorado que investiga o potencial da dança circular como mobilizadora da expressão de afetos e de reflexões que resultem na ampliação da consciência dos professores da rede pública de ensino. Nossos sujeitos são dois grupos de professores das redes municipal e estadual do interior de São Paulo.Desenvolvida como ação da Psicologia Escolar, a proposta é construída com base nos pressupostos teórico-metodológicos da Psicologia Histórico-cultural. Nosso método fundamenta-se no Materialismo Dialético e utilizamos as expressões afetivas como unidade de estudo baseando-nos nas reflexões de Vigotski. Os dados apontam que o sofrimento no trabalho docente é grande, mas as danças circulares, respaldadas nos conceitos de Vigotski, podem se converter em porta de acesso à afetividade dos sujeitos e, assim, viabilizar a configuração de novos sentidos e significados - caminho este para o desenvolvimento da consciência.
\end{abstract}

Palavras-chave: Psicologia Histórico-Cultural; psicologia escolar; consciência.

\section{Body and teaching: a circular dance as a promoter of development of consciousness}

\begin{abstract}
This paper presents the results of a doctoral research investigating the potential of circular dance as mobilizing the expression of emotions and reflections that result in increased awareness of teachers of public schools. Our subjects are two groups of teachers from municipal and state of São Paulo. Developed as an action of School Psychology, the proposal is built on the theoretical and methodological assumptions of Historicalcultural psychology. Our method is based on the Dialectical Materialism and use affective expressions as unit of study based on the reflections of Vygotsky. The data show that the suffering in teaching is great, but the circle dances, backed the concepts of Vygotsky, can become affectivity access door of the subjects and thus enable the configuration of new meanings - this way the development of consciousness.
\end{abstract}

Keywords: Historical-Cultural Psychology; school psychology; consciousness.

\section{Cuerpo y docencia: la danza circular como promotora del desarrollo de la consciencia}

\section{Resumen}

Este estudio presenta los resultados de una investigación de doctorado que investiga el potencial de la danza circular como mobilizadora de la expresión de afetos y de reflexiones que resulten en la ampliación de la consciencia de los profesores de la red pública de enseñanza. Nuestros sujetos son dos grupos de profesores de las redes municipal y estadual del interior de São Paulo. Desarrollada como acción de la Psicología Escolar, la propuesta es construída con base nos presupuestos teórico-metodológicos de la Psicología Histórico-cultural. Nuestro método se fundamenta en el Materialismo Dialéctico y utilizamos las expresiones afectivas como unidad de estudio basándonos en las reflexiones de Vygotsky. Los datos apuntan que el sufrimiento en la labor docente es grande, pero las danzas circulares, respaldadas en los conceptos de Vygotsky, pueden convertirse en puerta de entrada a la afectividad de los sujetos y, así, viabilizar la configuración de nuevos sentidos y significados - camino éste para el desarrollo de la consciencia.

Palabras clave: Psicología Histórico-Cultural; psicología escolar; consciencia 


\section{Introdução}

Este artigo origina-se de uma pesquisa de doutorado que investiga a potencialidade de intervenções que se utilizam de expressões artísticas na promoção de reflexões e que resultam em ampliação da consciência dos sujeitos. Objetivou-se analisar o potencial da arte, neste caso, a dança circular,como mobilizadora da expressão de afetos e potencializadora do processo de desenvolvimento dos sujeitos que resultem na configuração de novos sentidos sobre a docência e na ampliação da consciência dos professores sobre sua condição de trabalho. Teve como sujeitos dois grupos de professores de duas escolas públicas do interior de São Paulo - uma municipal e outra estadual.

Desenvolvida como ação da Psicologia Escolar, a proposta foi construída com base nos pressupostos teórico-metodológicos da Psicologia Histórico-Cultural, que propõe o estudo do homem a partir de uma relação dialética de interdependência entre múltiplos aspectos que se engendram no processo de constituição do sujeito, no qual o meio tem papel fundamental. Para Vigotski (1927/2004a, 1935/2007), um de seus principais representantes, o contexto em que o sujeito está inserido é uma espécie de trama que respalda seu desenvolvimento físico, afetivo e social de forma imbricada.

Outro aspecto abordado nas obras de Vigotski (1925/2001) e que embasou esta investigação é o destaque conferido à afetividade e ao potencial da arte em acessar o sensível nos sujeitos, o que se constitui condição à ampliação da consciência. E, para o autor, a arte pode ser um caminho para se acessar a afetividade.Vigotski(1925/2001), em seu livro 'Psicologia da Arte', descreve que a arte confere significado às emoções e movimento a aspectos outrora adormecidos, pois tem o poder de catalisar os sentimentos, percepções, impulsos e eleva a predisposição à ação - um caminho para o desenvolvimento da consciência. Mas o que é consciência?

Este trabalho toma o conceito de consciência como função psicológica superior que integra as demais funções, resultando em uma síntese que caracteriza o modo de saber-se de si, do outro e do mundo, inserindo-se e posicionando-se nas relações concretas que estabelece com a realidade. Neste sentido, a consciência é condição para o desenvolvimento do pensamento crítico do sujeito e como função do psiquismo ela emerge das e nas relações sociais, sendo os grupos de que participa o sujeito, o meio favorecedor desse modo de ser e agir da pessoa. A consciência de nossas ações faz com que sejamos capazes de dominá-las, interferindo e transformando-as e, assim, podendo agir e recriar a realidade (Vigotski, 1933/2004b).

Pensar uma forma de arte que mobilizasse a expressão da afetividade e o desenvolvimento de consciência crítica pelos professores nos levou a pesquisar formas de danças que fossem feitas em grupo; neste caso, a dança circular foi a manifestação artística que elegemos.

\section{Passos de uma dança}

As danças circulares derivam de culturas de várias partes do mundo eforam coletadas por um bailarino alemão, Bernard Wosien (2000), que viu em suas características potencial para se trabalhar com grupos, pois são dançadas conjuntamente em roda e, por seu ritmo e coreografia simplificada, são relativamente fáceis de serem executadas em conjunto. Além disso, todas possuem simbolismos dos seus povos de origem e trazem a propriedade de evocar no grupo que dança estas características; algumas despertam alegria, outras, introspecção, ou entrega, brincadeira, reverência, além da amizade e do contato afetivo, entre outros aspectos.

As danças circulares não são meramente folclóricas, mas remetem a um trabalho que busca, por meio do dançar em roda, do gestual, da coreografia, do ritmo e da música, acessar a subjetividade humana e provocar vivências que possibilitem que o sensível emerjae seja compartilhado por um grupo (Wosien, 2000). Para que este processo se estabeleça, há algumas peculiaridades na forma das danças circulares que facilitam o fluir da roda e o contato consigo e com o outro. Inicialmente, nos ordenamos em círculo com as mãos dadas, mão esquerda voltada para baixo, palma da direita para cima em um simbolismo de receber e doar que se fecha em um circuito. A disposição na dança de roda depende desta para se mover em torno de um centro; compasso, ritmo e melodia da música ou de um canto entoado por todos que motivam o movimento e a sequência de passos em uma combinação de posturas, repetições de movimentos articulados com saltos, gestos e giros. Wosien (2002) destaca que esses aspectos também guardam um simbolismo do paroxismo da vida e são representados pelos movimentos na alternância da tensão e relaxamento, do erguer e abaixar os braços, do ir para frente e para trás, de um jogo de forças e leveza que se revezam na dialética humana.

Alguns trabalhos acadêmicos no Brasil vêm sendo feitos corroborando com a percepção de Bernard Wosien do potencial de setrabalhar com grupos por meio das danças circulares. Almeida (2005) fez sua tese de doutorado no campo da saúde sobre os benefícios destas danças na promoção da qualidade de vida e sua relação com a ressignificação da imagem corporal entre as participantes. Ostetto $(2006,2010)$ utiliza as danças circulares como mediadoras da expressão dos afetos dos professores em curso de pedagogia e declara que o gestual, a coreografia, o movimento e a música são postos como uma forma de esvaziar a atenção e deixar a consciência emergir por meio de outra linguagem. Outras pesquisas revelam uma interface sobre as danças circulares, as quais, segundo os autores, por suas características, podem representar um espaço significativo para o desenvolvimento de estados emocionais positivos em pesquisa com adolescentes (Catib, Trevisan, \& Schwartz, 2011) ou em pesquisa com idosos de um grupo da Terceira Idade (Catib, Schwartz, Christofoletti, Santiago, \& Caparroz, 2008). Os autores destacam que as danças circulares têm o potencial para se tornar um recurso importante no contexto grupal, uma vez que despertam o respeito ao outro, a integração, 
a inclusão e o acolhimento às diversidades e estimulam a cooperação.Como recurso didático na escola, as danças, pelas características integrativa e cooperativae, ainda, por permitirem a emersão de aspectos sócioafetivos, podem respaldar a disseminação de valores importantes no contexto educacional (Catib, \& cols., 2011; Ostetto, 2006, 2010).

Percebe-se que há uma plausibilidade de trabalho da Psicologia com a dança dentro de contextos variados, tendo em vista seu potencial para tocar a subjetividade dos sujeitos que transcendem o corpo, o lazer ou o folclórico justamente por ser uma atividade mediadora, capaz de provocar a emersão e manifestação de intrasubjetividades e intersubjetividades. Deste modo, acreditamos que as danças, respaldadas nos conceitos de Vigotski, podem se converter em porta de acesso à afetividade dos sujeitos dentro da escola e, assim, viabilizar a configuração de novos sentidos e significados - caminho este para o desenvolvimento da consciência.

\section{Método}

Esta pesquisa fundamentou-se no Materialismo Dialético que focaliza a complexidade e as contradições constituintes dos fenômenos humanos. Para investigá-los por meio desta perspectiva é necessário observar o movimento dialético tomando como fonte o social de cada momento vivido (Vigotski, 1927/2004a). Para Vigotski (1925/2001), é justamente no termo vivência que podemos compreender a relação entre sujeito-meio de forma indissociável.

Vigotski (1933/2006) afirma que nas vivências afloram todas as propriedades da pessoa construídas em seu processo de desenvolvimento, pois abarca uma integração constituída pela personalidade do sujeito inserido em uma situação social de desenvolvimento ${ }^{1}$ específica. Sugere o autor que esta relação possa ser apreendida utilizando-a como unidade de análise da consciência humana (Vigotski, 1925/2001).

Assim sendo, acategoria teórica vivência, entendida como interação entre sujeito - personalidade - consciência - meio (Vigotski, 1933/2006) e constituída por emoções intensas, pode ser acessada por meio das expressões afetivas dos sujeitos, que seriam tomadas como indicadores de vivência.Para promovermos vivências utilizamos estratégias de pesquisa e intervenção desenvolvidas por nosso grupo de pesquisa ${ }^{2}$ denominadas de materialidades mediadoras, que são procedimentos em que se vivenciam várias formas de manifestações artísticas como forma de aproximação dos sentidos configurados pelos sujeitos em relação aos fenômenos investigados (Souza, Petroni, \& Dugnani, 2011).

1 Segundo Vigotski (1933/2006b), para haver vivência é necessária uma situação que a suscite e que não se configura como externa, mas como movimento relacional entre o interno e o externo, uma situação única, que ele denomina de situação social de desenvolvimento.

2 PROSPED (Processos de Constituição do Sujeito em Práticas Educativas) da Pontifícia Universidade Católica de Campinas.
Esta pesquisa tem como sujeitos dois grupos de professores: um de uma escola de Ensino Fundamental I, da rede municipal de uma cidade do interior de São Paulo; outro formado porprofessores de uma escola de Ensino Fundamental II, da rede estadual de outra cidade do interior de São Paulo. Chamaremos a Escola municipal de Escola 1 e a estadual de Escola 2. A gestão de ambas as escolas se interessou pelas estratégias desta pesquisa-intervenção pelo fato delas focalizarem o corpo, os afetos, fazendo uso da dança, vendo nelas novas possibilidades de formação e acreditando em seu potencial para a promoção de mudanças do modo de pensar e agir dos professores, que se diziam cansados de discutir textos e refletir sobre eles.

\section{Nossa forma de ação}

Os encontros aconteciam nos horários das escolas dedicados à formação de professores ${ }^{3}$. A intervenção era aberta com algum tipo de aquecimento que incluía movimentos corporais, em seguida, passávamos para a explicação da dança que faríamos, tanto em seu simbolismo, como os passos e o ritmo. As danças foram escolhidas previamente pela pesquisadora conforme o que se planejava vivenciar em cada encontro, com o intuito de resgatar o motivo tradicionalmente conferido àquela dança. Em seguida abria-se espaço para conversarmos sobre a vivência de cada um (roda de conversas) ou para a escrita espontânea/anônima (reflexões escritas) ambas como canal de expressão e comunicação de afetos, percepções, questionamentos e, também, fonte de dados para a pesquisadora.

As informações coletadas partiam da observação e de seu registro em diário de campo construído após cada encontro pela pesquisadora. A partir dos diários, o movimento foi o de buscar identificar as expressões afetivas atreladas ao fenômeno investigado e, de posse destes dados, foram feitos recortes mais pertinentes ao objetivo de pesquisa. As expressões afetivas deram origem às subcategorias que foram agrupadas em torno de três grandes categorias: Desamparo/Amparo; Desgaste/Disposição; e A Dança como Promotora da Consciência do Professor.

Concernente à metodologia do Materialismo Dialético, objetivou-se analisar as contradições relativas ao modo como os professores lidam com os afetos na escola, e esta opção nos conduziu a proceder à análise por pares de opostos porque se observou que a expressão de afetos negativos esconde afetos positivos e vice-versa.

\section{Resultados}

Por meio dos indicadores de vivências (expressões afetivas) foi possível desvelar questões relativas ao traba-

3 TDCs (Trabalho Docente Coletivo) e HTPCs (Horas de Trabalho Pedagógico Coletivo) são espaços de formação continuada; o primeiro da escola municipal, e o segundo, da rede estadual de São Paulo. 
Iho docentedistribuídas em três categorias. Na categoria Desamparo/Amparo, discorre-se sobre as vivências dos professores ao terem de enfrentar os desafios da escola sem parcerias, com sentidos de solidão, sofrimento e frustração. Em contraponto, deixam entrever a necessidade de união entre os integrantes da escola. Na categoria Desgaste/Disposição discorre-se sobre as vivências dos professores em relação à sua profissão com sentidos de perdição frente aos desafios, opressão pelas imposições políticas, esgotamento físico/afetivo e desmotivação provocados pelas condições materiais que caracterizam o trabalho docente. Diante de tantas situações de desgaste, os sujeitos engajam-se nas propostas da intervenção com as danças por promoverem tranquilidade e entrega. Finaliza-se com uma síntese do trabalho na categoria: A Dança como Promotora da Consciência do Professor.

\section{Vivência da docência como DESAMPARO/ AMPARO}

A vivência da docência como desamparo se expressa por meio de indicadores que conferem à profissão o sentido de solidão, sofrimento e frustração. Esses afetos, experimentados com frequência pelos sujeitos nas práticas cotidianas da escola, é que configuram a docência, na visão dos professores, como profissão difícil e sofrida.

\subsection{Solidão}

Os dados coletados indicam que a solidão se expressa na escola pelo sentimento de ter de "se virar" sozinho, pela falta de parcerias e apoio. Os relatos dos professores das escolas 1 e 2 apontam que a solidão é vivida de modo recorrente e, pela densidade das expressões, revelam uma situação de sofrimento que parece caracterizar o contexto educativo em que atuam. Descrevem aspectos como: "tudo cai nas costas dos professores"; "não temos com quem dividir"; "se o professor não consegue lidar com os problemas em sala de aula é um problema de perfil"; "se o aluno tem problemas é porque o professor não dá conta” (Diário 12 - Escola 2).

O sentido que prevalece na prática docente é de que ela depende do indivíduo, neste caso, do professor: ele se vê como único responsável por saber ou não saber lidar com seus problemas. Contraditoriamente, os professores se queixam da falta de parcerias, mas eles mesmos atribuem o conseguir ou não lidar com os conflitos dentro da escola a características individuais, como se fosse um 'problema de perfil'. Logo, só compete a eles resolver os problemas que enfrentam.

De acordo com Souza, Petroni e Andrada (2013), os professores configuram o sentido de docência atrelado ao sentimento de solidão, ou seja, identificam esta profissão como solitária pela falta de apoio nas múltiplas esferas da escola - gestão, família, aluno, sociedade, Secretarias da Educação, conforme será apontado no decorrer desta aná- lise. A conjunção de tais aspectos contextuais e o quanto eles podem interferir no trabalho pedagógico parece não ser percebido pelos professores e produz uma condição de sofrimento que caracteriza a atividade docente.

\subsection{Sofrimento}

As falas expressam o sofrimento atrelado à concepção dos professores sobre a docência e revelam o quanto os sujeitos veem seu trabalho como algo difícil e desprestigiado e o sofrimento atribuído ao ser professor assume a configuração de "profissão de risco" com falas como: "temos de nos vestir com uma armadura dura e inflexível'," "o professor doa tudo o que pode, sem ter retorno"; "continuamos a bataIha"; "antes os professores eram referência, hoje não é mais assim"; "o professor é um m... para o aluno"; "a profissão passou a ser considerada de risco"; "ninguém mais quer dar aula: virou sim profissão de risco" (Diários 03 e 05 - Escola 2).

A vivência de desamparo configurada pelo sentido de solidão e as grandes demandas postas à Educação e não atendidas pela escola podem ser geradoras de sofrimento, muitas vezes percebido pelo professor com um peso maior do que em outras profissões. Segundo Charlot (2008), o professor se vê "por um lado, o herói da Pedagogia. Por outro, a vítima, mal paga e sempre criticada" (p.22), tanto que um dos professores diz: para a sociedade o "professor é um m.", atribuindo uma ofensa a esta profissão. Souza e cols. (2013) apontam que, para dar conta de tamanha demanda e pressão, os professores desenvolvem posturas defensivas de vitimização: "diante da sensação de abandono, solidão, injustiça e revolta, resta ao professor, impotente, postar-se como vítima de uma situação em que não há culpados, mas sim, responsáveis pela proliferação de uma conjuntura crítica da Educação brasileira" (p.532).

Nossa hipótese é que diante de um contexto conflituoso, os professores desenvolveram uma representação para contornar o desamparo, a solidão e outros desafios da profissão. E uma das expressões afetivas que se interligam ao sofrimento é a frustração por tantas expectativas e necessidades não realizadas.

\subsection{Frustração}

A vivência da docência como desamparo encontra suporte também no sentimento de frustração que permeia as práticas docentes. Os conflitos sobre o papel de educar queseria de competência da família e é repassado para a escola e a falta de recursos mínimos para o trabalho em sala de aula se revelam como frustração em relação a não concretização das expectativas dos professores: "o abandono da educação em casa tem um reflexo muito grande na escola", "há ausência de um respaldo familiar para um melhor aproveitamento do aluno"; "a irresponsabilidade da família é o que me entristece na Educação"; "a estrutura da escola que não comporta maneiras alternativas de trabalhar e tem 
a dificuldade em perceber e oferecer o que é conhecimento realmente significativo aos alunos" (Diário 10 - Escola 1).

Parece que o professor, ao não dar conta de uma demanda que não é só sua, sucumbe à frustração que surge com contornos de algo desejado, mas não atingido, complementando o que apontamos até o momento sobre a tarefa da Educação como profissão solitária, contradição que emerge de algo que só se efetiva no coletivo.

O professor mostra-se comprometido com os resultados da educação, mas como é falho, resta frustrar-se. Leontiev (1975/1985) aponta que para o trabalhador o sentido pessoal está interligado ao conteúdo da ação e ao seu motivo; a ação isolada sem a noção de finalidade, significação e pertencimento a uma coletividade se esvazia de motivo. As condições de existência impõem uma escola esvaziada de sentidos para os seus integrantes, pois as relações são desconexas, não representando efetivamente uma atividade, consequentemente, não há muito pelo que lutar ou fatores que propulsionem a ação conjunta e as relações de amparo mútuo. Tampouco se pode delegar culpa a alguém, pois o esvaziamento de motivos, afetos e sentidos se refere à dinâmica escolar de maneira sistêmica.

Todos esses aspectos descritos até o momento e constituintes de relações de desamparo demandam intervenções que priorizem as ações de amparo, troca e união. Wosien (2000) observou o potencial das danças circulares em promover o fortalecimento dos grupos e foi justamente por esta característica e pela possibilidade de acessar o sensível que propusemos este tipo de atividade nas escolas. Wosien (2002) revela que as danças em roda se constituem como uma das manifestações artísticas mais antigas da nossa civilização e acreditamos que seu poder de mobilizar e de unir as pessoas há tantos séculos permanece na atualidade, como se demonstrará adiante neste artigo.

\subsection{Sentimento de união/Confraternização}

Buscando olhar para os fenômenos de uma perspectiva dialética, é relevante evidenciara emersão no grupo de expressões afetivas positivas em contraponto ao desamparo. Apesar de haver um volume muito maior de expressões negativas nos relatos, também houve manifestações de sentimentos de união e confraternização nos grupos suscitados por meio da dança: "a dança evocou a alegria e a socialização"; "senti uma sensação de pertencer a um grupo através daquela grande roda" (Diário 02-Escola 1). Ou ainda: "pude olhar para o outro e ser olhada. Senti-me valorizada por isso [...] Senti-me reconhecida"; "senti alegria e prazer por estar compartilhando com todos aquela dança"; "achei prazeroso dividir esta sensação de união com o grupo" (Diários 06 e 10 - Escola 2).

Dialeticamente, em contrapartida ao sentido de desamparo, os grupos revelam a existência de uma dinâmica de união. Para Wosien (2002), uma das propostas da dança circular é colocar o sujeito em um espaço de contato consigo e com o outro. Concernente aos relatos, a dança pode favo- recer vivências de interação: o formato da roda, a proximidade entre as pessoas, e todos dançando a mesma coreografia são aspectos que contribuem para uma experiência grupal. Ainda, esta prática guarda uma série de representações que podem ser acessadas pelos dançarinos durante sua execução (Wosien, 2002), constituindo-se em uma vivência que mobiliza o compartilhar de afetos entre as pessoas.

Mas os desafios são por demais complexos, visto que a dinâmica do sistema educacional tem grande influência na criação e manutenção das condições de trabalho que provocam o desamparo. Fato é que as expressões de união são um contraponto para as expressões de solidão, sofrimento efrustração vivenciados em outros momentos ou de modo concomitante, provocando uma situação tão desgastante que o professor parece não dar conta, o que interfere em sua disposição para agir. É sobre esta dimensão, que caracteriza a vivência da docência como desgastante, que discorremos a seguir.

\section{Vivência da docência como DESGASTE/ DISPOSIÇÃO}

Percebe-se um movimento progressivo que emerge das vivências da docência pelos professores: o desamparo vivido de modo recorrente parece ir construindo o desgaste em relação à profissão, caracterizado pelo sentimento de perdição por não saber o que fazer ante as dificuldades na escola e de opressão diante das imposições políticas, os quais resultam em esgotamento e desmotivação por terem que sobreviver em tal contexto. Dialeticamente, os professores engajam-se nas propostas com o corpo e a arte, pois percebem os ganhos e resultados dos momentos de parada de nossas intervenções, traduzindo-os em expressões de tranquilidade e entrega.

\subsection{Perdição}

As falas trazem expressões afetivas sobre a dificuldade do docente diante da falta de perspectiva em relação ao presente ou futuro da Educação, configurando um sentido de perdição diante de tal contexto. Expressam questões como: "a escola não é mais a mesma e não entendo o porquê"; "por que a escola mudou?"; "os pais não colocam mais limites"; "as famílias são desestruturadas"; "o governo não liga para a Educação"; "as escolas estão largadas"; "antes, ser professora era o máximo, hoje, ninguém quer" (Diário 06 - Escola 1); "a Educação mudou e o professor não está preparado para ela"; "a questão não é de conteúdo, mas de lidar com os conflitos dentro de sala de aula e a faculdade não ensina o professor a lidar com isto" (Diário 03 - Escola 2).

Os relatos revelam situações em que os docentes não sabem que algo estrutural mudou, mas se veem impotentes porque não conseguem identificar com precisão a natureza dessas mudanças, nem tampouco o modo como elas interferem em suas ações educativas. Da perspectiva 
teórico-metodológica adotada neste trabalho, (Vigotski, 1927/2004a, 1935/2007), considera-se que a concepção dos professores diante da realidade escolar é um processo que envolve as condições políticas e sociais de nosso país e, logo, não como resultado somente da ação docente. Mas os professores, ao mesmo tempo em que sabem disso, esquecem-se de que não mudam o contexto sozinhos e de que não são os únicos responsáveis pelo destino de nossa Educação. Pode residir aí parte de seu desgaste, por não saberem para onde ir, se fazem algo para mudar, se esperam alguma transformação da esfera pública ou se calam diante de algo para o quê não veem solução.

Compreendem-se aqui alguns aspectos na escola provocadores de perdição e, também, fatores que estão na base do desgaste que caracterizam o modo desses professores viverem sua profissão. Há também outro elemento abalizador desta relação: a sujeição às imposições de políticas educativas vividas como opressão.

\subsection{Opressão}

As expressões que aqui se revelam assinalam o mal-estar vivido pelos docentes frente às políticas públicas para Educação como parte de um movimento constituinte do desgaste dos professorescomo os expressos nos relatos: [desgasta]"notar que tudo é política e a última coisa que importa é o aluno aprender e conseguir mudar algo em si e a sua volta"; "o grande vilão dessa relação é o próprio serviço público, que não enxerga a Educação como um instrumento de transformação"; "tudo na Educação Pública é um disfarce e não deve dar certo" (Relatos anônimos - Diário 10 - Escola 1); "o Governo impõe coisas lindas no papel, mas não preparam o professor para isto"; "ninguém nos escuta porque só nós sabemos o que passamos aqui, se algo é bom para a escola, o que dá certo e o que dá errado"; "quem está lá de cima não faz a menor ideia do que acontece aqui e do que é preciso mudar" (Diário 01- Escola 2).

Percebe-se um sentido configurado pelo professor na esfera pública que não preconiza o outro e revela um conflito vivenciado na profissão: mesmo criticando o meio em que está inserido, sabendoda necessidade de mudanças, sente-se impotente diante da máquina do Estado que gere o sistema educacional.

Os professores apreendem que quem faz a escola não são eles, que estão ali todos os dias convivendo com uma realidade que conhecem e sabem bem dos reais desafios, mas eles devem acatar medidas sem terem participação na construção destas. Esta não inclusão do outro no andamento, na forma, nos objetivos e nas funções da Educação e tratar a Educação com este nível de fragmentação e distanciamento são aspectos que a enfraquecem. $O$ que reflete a realidade brasileira é a deficiência no ensino e no aprendizado, o despreparo do aluno e do professor, a desvalorização e desrespeito ao educador, desvelando aspectos próprios da organização histórico-social das escolas brasileiras (Libâneo, 2010).
Este fazer conflituoso gera um processo cíclico: a condição de trabalho desfavorável emerge como um dos aspectos que fomentam o sofrimento docente expresso pelo esgotamento do professor, que, a um só tempo, está na base de uma ação esvaziada, pois o professor exausto não produz, não se implica e, comumente, trabalha em seu limite físico, emocional e mental.

\subsection{Esgotamento}

Esta complexidade do contexto educacional se revela também em relatos em que se explicita a falta de vitalidade para empreender a tarefa: "não sei como estou de pé, tenho casca grossa, mas estou acabada"; "não tenho tido vontade de vir para a escola e nem aguento levantar da cama"; "o corpo não responde de tão cansada que estou"; "me sinto exausta, sem energia para nada” (Diário 10 - Escola 2).

Estas falas simbolizam a variedade de situações adoecedoras no cotidiano escolar. Mas por que se desgastam tanto? A saída é só pelo adoecimento ou endurecimento? Sawaia (2010) aborda o sofrimento da perspectiva da Psicologia Histórico-Cultural e entende que as dores em nossa sociedade revelam um sofrimento que é reprodução de problemáticas sociais, ideológicas e históricas. Essa concepção coloca o sofrimento como dor mediada pelo social em que cada período temporal do desenvolvimento da sociedade abarca aspectos contextuais diversos que afetam as pessoas de formas variadas. Assim sendo, o que, afinal, há na atualidade dentro da Educação que esgota tanto seus trabalhadores?

Os dados desta pesquisa nos ajudam a entender que, apesar de o professor falar sobre seu esgotamento, trazendo para o indivíduo a responsabilidade do dar ou não conta, quem precisa de cuidados é a instituição Escola, conforme Souza (2005, 2013), Charlot (2008) e Libâneo (2010) descrevem. O esgotamento é do indivíduo, mas sua origem, conforme aponta Sawaia (2010), está no âmbito sociopolítico.

Discutir esta questão importa se o que se intenta é promover o desenvolvimento da consciência dos professores, pois questionar pode iluminar as situações controversas com as quais os integrantes da escola têm se deparado. Destas, os dados levantados indicam que há um movimento que se generaliza nas duas escolas: diante do sofrimento, solidão, frustração, perdição e opressão, o professor se esgota e se desmotiva.

\subsection{Desmotivação}

Conforme os relatos, o desamparo e desgaste parecem provocar um esvaziamento do sujeito e de sua prática, como mostrado nos exemplos que se seguem, ambos no final do ano letivo: "praticamente todas as professoras pediram remoção [para outra escola]"; "antes as professoras eram mais unidas e, hoje, ao invés de tentarem melhorar 
a situação, apenas pedem remoção de escola"; "uma das professoras pediu transferência, pois não aguentava mais aquela escola" (Diário 06 e 15 - Escola 1).

O que há por trás destas cenas em que o movimento não é de transformação, mas de perda de potência, de desistência? A saída da maioria dos professores apontaria uma não ação em relação a esta escola, uma desistência. Mas por quê? Martins (2011) traz uma condensação da relação que Vigotski, Leontiev e Bozhovich, representantes da Psicologia Histórico-Cultural, fazem entre afeto e atividade: "o afeto corresponde a processos emocionais relacionados às necessidades e atividades que se opõe à passividade ou indiferença do sujeito em face do objeto, compreendendo estados dinâmicos de caráter profundo e prolongado, podendo tanto orientar quanto desorganizar o comportamento" (Martins, 2011, p. 205).

Remetendo ao professor, no final do ano letivo, ao não ver os resultados de seu trabalho, ao não conseguir interferir em um contexto que pouco se desenvolve, não é possível atribuir real valor a sua atividade. Para a adesão a qualquer trabalho, se faz necessário o reconhecimento e validação da ação como necessária. Porque a necessidade gera os motivos e os motivos geram a necessidade. A própria necessidade reforça esse motivo, confere mais força, sustenta e cria outra necessidade. Motivação é afeto, está ligado ao desejo e à vontade (Leontiev, 1975/1985). E quando o professor não vê motivos suficientes para empreender sua prática, o que este processo pode desencadear? Ter que se inserir em uma atividade sem sentido provoca a perda de potência, de desejo, de vontade, e manter-se nesta dinâmica desgasta, então ele desiste, se aliena.

Martins (2004) assinala que o sujeito dentro de um processo alienante pode promover sua ruptura ao engendrar novos sentidos promotores de motivos, permitindo que o sujeito reveja suas condições de trabalho e amplie a consciência de si abrindo precedente paraa práxis transformadora. Um de nossos objetivos é justamente propor esta pausa para reflexões sobre si, o outro e a escola. E haja vista que a dança faz parar para pensar, as escritas e as falas idem, talvez, estes podem ser instrumentos interventivos capazes de frear o processo alienante e oferecer uma pausa provocadora de reflexão inicial, passo primeiro para a consciência.

A relevância da dança circular se mostra ao tirar os sujeitos do seu modus operandi e os colocar em uma situação diferenciada, menos passiva. Apesar dos encontros terem suscitado tantas expressões afetivas negativas de desgaste, o movimento de análise das contradições revela que, paradoxalmente, a expressão de afetos negativos desencadeou a vivência de afetos positivos e, no caso deste tópico, em específico, de sentidos de tranquilidade e entrega.

\subsection{Tranquilidade}

Vê-se que, por meio da arte, consegue-sepromover a emersão de afetos e abrir possibilidades de reflexões menos automatizadas, possível caminho para o desenvolvimento da consciência. Relatos como: "antes da dança, estava agitada interiormente e após e durante a dança senti tranquilidade" (Diário 10 - Escola 2);"gosto muito dos momentos de 'desativar' nossa rigidez tanto corporal como emocional", "senti-me muito bem; também o corpo ficou mais leve" (Avaliação final - Escola 1);"adorei! É ótimo para relaxar e para desligarmos um pouco a mente da rotina do dia a dia estressante"; "foram momentos bem agradáveis de descontração e relaxamento" (Avaliação final- Escola 2).

Seja pela introspecção, pela expansão, ou pela retirada do sujeito de seu processo de desgaste, a dança tem se mostrado uma materialidade de acesso à subjetividade do docente por meio de veículos como o corpo, o ritmo e a música. Para Vigotski (1925/2001), por meio da arte a emoção nos liberta dos recalques, orienta, motiva, dá novas forças e possibilita uma organização do nosso comportamento, conferindo um significado às nossas emoções, que, por sua vez, possuem uma tendência de traduzir-se em forma de ação, pois a arte faz manifestar a vontade, elevando essa predisposição à ação.

Segundo Vigotski (1933/2006), é por intermédio da vivência que a configuração de novos sentidos sobre o vivido em determinada situação se torna possível e, portanto, ponto de partida para possíveis mudanças, inclusive esta promover o bem-estar em um contexto sabidamente tenso, árido, endurecido. De tal modo, destaca-se a importância de trabalhos deste teor que ofereçam novas situações sociais de desenvolvimento dentro das escolas para que o sujeito enrijecido, cansado, com dificuldade de se expressar e se soltar possa ter contato com um meio que ofereça a ele outras possibilidades para transpor este estado de desgaste com a perspectiva de transformá-lo em entrega.

\subsection{Entrega}

Nota-se as danças circulares como promotoras de vivências significativas para o professor, permitindo-lhe romper com o desgaste relatado. Mediante os diários, vê-se uma quantidade de dados com descrições de muitos afetos positivos impactantes, por isso, constituindo-se como vivências, suscitadas pela entrega às danças circulares como: "[quando dança] a gente esquece tudo e se torna outra pessoa"; "antes, estava apreensiva, [...] depois, senti paz, centramento, brotar a essência, religar os corpos, entrar na luz"; "me senti em reencontro com a graça (alegria) de ser! AGRADECIDA e merecedora da graça de passar por este momento"; "senti-me impulsionada, fechei os olhos e fui levada [...] a vontade que senti foi de fazer uma oração, conversar com Deus, e foi o que eu fiz. Senti vontade de chorar. Por alguns momentos não pensei em nada, depois as palavras foram vindo. Foi lindo" (Diário 06 e 10 - Escola2).

Compreende-se que se os professores mudaram suas expressões afetivo-corporais durante as práticas, isso se deu pela capacidade que a dança circular tem de promover contato com as qualidades intrínsecas a ela (Wosien, 2000). Por esta via mais sutil de expressão, nos momentos 
em que havia uma tensão ou rigidez inicial, as práticas viabilizaram quebras, quer seja pela topologia de alegria, soltura, leveza, brincadeira, ou por rir dos próprios erros, indicando o sentido de entrega. Não seriam estes também indicadores de que houve vivência?

A dança também tirou os professores da desmotivação causada pelo desgaste e trouxe nova disposição: "confesso que cheguei cansada e quando vi que era a dança fiquei torcendo para não dançarmos, mas foi muito bom ter dançado, me renovei!"; "também não queria dançar e depois gostei muito de ter dançado"; "senti que esta dança foi um alimento"; "estávamos acabadas e saímos revigoradas" (Diário 06 - Escola 2).

Se em alguns momentos há resistência ou cansaço, quando participam, colhem os benefícios da atividade e saem revigorados, corpo e afeto, sujeito e grupo. Os professores revelam ânimo, leveza, alegria, entre outras expressões afetivas, mas o sentido foi de entrega e envolvimento com a proposta, tudo isso denotando que haviam sido tocados. Prestes (2010), embasada em Vigotski, diz que: "toda atividade precisa de uma fonte de energia que a alimente" (p. 273). Essa energia é o afeto que se manifesta em forma de motivo, de desejo. E o que vimos foi o grupo vivenciando a dança como potência, propulsora de afetos que azeitam o corpo cansado e mobilizam motivos adormecidos, despertando sentimentos intensos.

Porém, esta adesão ocorre com recuos e avanços e esse fato ratifica a compreensão sobre o desenvolvimento humano como processo dialético e o que se quer crer é que o movimento de reflexão sobre as condições da Educação continua apontando que as idas e vindas no processo de conscientização ganham novas qualidades, mais ampliadas. Ao finalizar esta categoria de desgaste/disposição fica a certeza de que é possível mobilizar os corpos - afetos - grupos por meio da arte. Porém, provocou-se ampliação da consciência?

\section{A dança como promotora da CONSCIÊNCIA do professor}

Esta pesquisa investigou a viabilidade do trabalho com o corpo na promoção da conscientização dos professores sobre suas condições de vida e trabalho. Poder impulsionar novas formas de expressão de sentimentos criou nos sujeitos condições de o afeto ser expresso e elaborado e, a partir daí, provocar pequenas transformações.

Entender o afeto é também entender como lidar com ele com o objetivo de promover nova consciência às emoções caóticas ou dispersas dos professores por meio da atribuição de novos sentidos ao vivido. Segundo Vigotski (1933/2004b), ter entendimento do que sentimos é compreender seu sentido e, para ele, é passo para o desenvolvimento da consciência. Percebe-se este movimento nos exemplos que se seguem: "uma das professoras disse que tem pensado em nossas práticas sempre que está estressada e diz que tem parado para respirar no trânsito, no trabalho e em casa" (Diário 06-Escola 1); "depois da dança me sinto mais focada e mais tranquila em relação à realização do meu trabalho"; "antes da dança, eu me sentia irritada, nervosa, muito tensa, sem vontade, com ansiedade, o coração estava acelerado. Agora parece que despertei", "a dança acaba tocando um pouco de nossa calma e paz interior" (Diário 10-Escola 2).

Revelou-se pelos encontros o que Vigotski (1925/2001) descreve sobre a arte como forma de dar contornos às emoções. A utilização da arte como signo, como linguagem diferente do rotineiro, pode funcionar como possibilidade de ir além do que os docentes estão acostumados. Bernard Wosien (2000) assinala que, pela livre manifestação de sentimentos, da pendulação entre movimento e calma, expansão e retração, o homem que dança tem a possibilidade de apropriar-se de si e do outro. Circulação, flexibilidade, respiração, equilíbrio, tensão e relaxamento, coadunados, fazem parte da dinâmica de tocar e ser tocado por meio das danças, segundo o autor.

Paralelamente, veem-se muitas falas sobre a relação entre as danças e o aumento de percepção sobre si e seu corpo, sobre a abertura para a busca de equilíbrio emocional e consciência de si e do outro como: "essas práticas despertam uma consciência corporal maior e aumentam, assim, as percepções das emoções e sentimentos"; "ajudou-me a restaurar o equilíbrio interno"; "aumentam as percepções emocionais e os sentimentos, alinhando a mente e o corpo"; "gosto muito das danças circulares; é o momento que mais consigo me desligar dos problemas do dia a dia"; "as danças circulares foram um exemplo de alívio físico e mental" (Avaliação final - Escolas1 e 2).

Vemos que o professor foi tocado em algum momento e neste processo descrito, nota-se a configuração de novos sentidos, que, para Souza e Andrada (2013), respaldadas na teoria de Vigotski, seria a própria manifestação de desenvolvimento da consciência. Segundo as autoras, quando se produzem novas conexões, cria-se também a configuração de novos sentidos provocando avanços no desenvolvimento do sujeito. Analisar a conexão entre as configurações de novos sentidos pelo professor e o desencadeamento de reflexão sobre sua condição é requisito para a ampliação da consciência e este processo só foi possível porque as situações sociais de desenvolvimento erigidas nas intervenções se configuraram como uma vivência.

Contrapondo-se ao desamparo e desgaste, os dados mostram que se obteve, pela vivência, a emersão de sentidos de confiança, união, entrega e tranquilidade permeados também pela esperança e motivação. Assim sendo, aprender a respirar, a relaxar, a se soltar pela dança foi, pela vivência, uma abertura de outras portas dentro da escola para a afetividade, ora tão à flor da pele, ora engessada, ora cindida entre corpo - afeto - cognição; e transpor este modo de ser e perpetrar mudanças (mesmo que pequenas) indica um processo de conscientização. 


\section{Conclusão}

No que concerne aos aspectos comuns às duas escolas, evidenciaram-se que as experiências positivas de amparo, disposição e promoção da consciência foram, comparativamente, menores em relação aos relatos de desamparo e desgaste, em ambas. Avaliando-se o volume e profundidade dos dados de uma perspectiva dialética, aponta-se a existência de uma lacuna nas interações dentro da escola: as expressões de afetos negativos foram mais proeminentes do que os positivos, sendo o sentido de sofrimento prevalente em todas as categorias, configurado com diferentes contornos, mas sempre caracterizado pela dor atrelada à docência.

Em contrapartida, os encontros ofereceram pausas para os professores viabilizando vivências da docência de outra perspectiva, mais positivas, favorecendo a reflexão crítica sobre o cotidiano. De modo geral, as práticas psicológicas mexem com o sujeito quando bem encaminhadas e promovem o desenvolvimento de consciência. Contudo, percebeu-se que a dança, especificamente, ao tocar o sujeito, constituiu-se em meio privilegiado para a ampliação da tomada de consciência sobre si e o outro, sobre as condições que caracterizam a vida e a profissão.

O que faz a vivência da dança ser singular é que quando a utilizamos, por suas características de mobilizar corpo e afeto, ela promove uma consciência que integra o sujeito com o coletivo, com as parcerias. O sujeito em círculos, de mãos dadas, toca e é tocado, olha para o corpo do outro, e é olhado, é reconhecido e entra em conexão com o grupo. Assim sendo, a dança provoca um tipo de consciência que vai além do saber-se de si - é saber de si mediado pelo outro, pelo coletivo do trabalho. E, quando o coletivo emerge por meio dela, não é possível ficar imune; há realmente um contágio que outras formas de intervenção da psicologia talvez não consigam provocar. Contágio este permeado pela leveza, outra característica específica das danças circulares. Também, coloca em movimento não só o corpo, mas um conteúdo afetivo implícito nas danças; as qualidades de cada dança mobilizam o grupo em direção a estas características sem esforço ou direcionamento, contribuindo para este sentido de contágio percebido.

Por tudo isto, percebe-se que as danças mexeram com nossos sujeitos, despertou afetos, promoveu muitas reflexões e ações foram plantadas, esperando-se que possam crescer como respostas futuras em forma de práticas mais efetivas na escola.

Porém, alguns limites e desafios foram apreendidos e importante se faz apresentá-los para futuras investigações. Um limite claro foi perceber a ineficiência e esvaziamento dos encontros de formação de professores (horário em que eram realizadas as atividades desta pesquisa). Eles não são valorizados como espaço de reflexão e parecem funcionar para cumprir determinações legais ou como complemento da formação acadêmica. Constituída como uma obrigação é também apreendida pelo professor como tal, e sem espaço para uma formação continuada que pre- conize o desenvolvimento humano dos professores não há transformação.

Outro desafio foi a inserção da psicóloga pesquisadora na escola, pois sempre teve de lutar por espaço, insistir para que os encontros acontecessem, para ter sala de trabalho, horário disponível. E esta é uma questão que se revela um grande desafio, não só para esta pesquisa, mas para todo aquele profissional que se dedica aos contextos educacionais - urge investir em espaço físico e simbólico para o trabalho do psicólogo escolar, nos estabelecimentos de ensino em parceria com a equipe de cada instituição e para o reconhecimento de sua relevância, tanto dentro das unidades escolares como nas políticas públicas que endossem essa vertente de ação.

\section{Referências}

Almeida, L. H. H. (2005). Danças circulares sagradas: imagem corporal, qualidade de vida e religiosidade segundo uma abordagem junguiana. Tese de Doutorado em Ciências Médicas, Universidade Estadual de Campinas, Campinas-SP.

Catib, N. O. M., Schwartz, G. M., Christofoletti, D. F. A., Santiago, D. R., \& Caparroz, G. (2008). Estados emocionais de idosos nas danças circulares. Revista Motriz, 14(1), 41-52.

Catib, N. O. M., Trevisan, P. R. T. D. C., \& Schwartz, G. M. (2011). As Danças Circulares no Contexto das Tendências Pedagógicas da Educação Física. Impulso, 19(48), 61-72.

Charlot, B. (2008). O professor na sociedade contemporânea: um trabalhador da contradição. Revista da FAEEBA - Educação e Contemporaneidade, 17(30), 17-31.

Leontiev, A. N. (1985). Actividad, Conciencia, Personalidad (2a ed.) Habana: Editorial Pueblo e Educación. (Trabalho original publicado em 1975).

Libâneo, J. C. (2010). A escola brasileira em face de um dualismo perverso: escola do conhecimento para os ricos, escola do acolhimento social para os pobres. Trabalho apresentado no $X$ Encontro de Pesquisa em Educação da ANPEd-Centro Oeste, Goiânia-GO.

Martins, L. M. (2004). A natureza histórico-social da personalidade. Cadernos CEDES, 24(62), 82-99.

Martins, L. M. (2011). O desenvolvimento do psiquismo e a educação escolar: contribuições à luz da psicologia Histórico-Cultural e da pedagogia histórico-crítica. Tese de Livre-Docência em Psicologia da Educação, Universidade Estadual de São Paulo, Bauru-SP.

Ostetto, L. E. (2006). Educadores na roda da dança: formaçãotransformação. Tese de Doutorado em Educação, Faculdade de Educação, Universidade Estadual de Campinas, Campinas-SP. 
Ostetto, L. E. (2010). Para encantar, é preciso encantar-se: danças circulares na formação de professores. Cadernos Cedes, 30(80), 40-55.

Prestes, Z. R. (2010). Quando não é quase a mesma coisa: Análise de traduções de Lev SemionovitchVigotski no Brasil - Repercussões no campo educacional. Tese de Doutorado, Universidade de Brasília, Faculdade de Educação, Brasília-DF.

Sawaia, B. B. (2010). O sofrimento ético-político como categoria de analise da dialética exclusão/inclusão. Em B. B. Sawaia (Org.), As Artimanhas da Exclusão - Análise Psicossocial e Ética da Desigualdade Social (pp. 99-119). Petrópolis: Vozes.

Souza, V. L. T. (2005) Escola e construção de valores: desafios à formação do aluno e do professor. São Paulo: Loyola.

Souza, V. L. T., Petroni, A. P., \& Dugnani, L. A. C. (2011). A arte como mediação nas pesquisas e intervenção em Psicologia Escolar. Em R. S. L. Guzzo, \& C. M. Marinho-Araújo. Psicologia escolar: identificando e superando barreiras (pp. 261-285). Campinas: Editora Alínea.

Souza, V. L. T., \& Andrada, P. C. (2013) Contribuições de Vigotski para a compreensão do psiquismo. Estudos de Psicologia, 30(3),355365.

Souza, V. L. T.; Petroni, A. P., \& Andrada, P. C. (2013). A Afetividade como traço da constituição identitária docente: o olhar da Psicologia. Psicologia \& Sociedade, 25(3), 527-537.
Vygotsky, L. S. (2001). Psicologia da Arte (2a Ed.) São Paulo: Martins Fontes. (Trabalho original publicado em 1925).

Vigotski, L. S. (2004a). O significado histórico da crise da psicologia. Uma investigação metodológica. Em: L. S. Vigotski, Teoria e Método em Psicologia (pp. 203-417). São Paulo: Martins Fontes. (Trabalho original publicado em 1927).

Vigotski, L. S. (2004b). O problema da consciência. Em L. S. Vigotski, Teoria e Método em Psicologia (pp. 171-189). São Paulo: Martins Fontes. (Trabalho original publicado em 1933).

Vygotski, L.S. (2006). La crisis de los siete años. Em L. S. Vygotski, Obras Escogidas IV - Psicología Infantil (2a ed., pp. 377-386). Madrid: Visor y A. Machado Libros. (Trabalho original publicado em 1933)

Vigotsky, L. S. (2007). A Formação Social da Mente: o desenvolvimento dos processos psicológicos superiores (7a ed.). São Paulo: Martins Fontes. (Trabalho original publicado em 1935).

Wosien, B. (2000). Dança: um caminho para a totalidade. São Paulo: Triom.

Wosien, M. G. (2002). Dança Sagrada: Deuses, mitos e ciclos. São Paulo: Triom.

\section{Sobre as autoras}

Paula Costa de Andrada (p.andrada@uol.com.br)

Doutora pelo Programa de Pós-Graduação Stricto Sensu em Psicologia como Profissão e Ciência da Pontifícia Universidade Católica de Campinas.

Vera Lúcia Trevisan de Souza (vera.trevisan@uol.com.br)

Professora Doutora e Pesquisadora do Programa de Pós-Graduação Stricto Sensu em Psicologia como Profissão e Ciência da Pontifícia Universidade Católica de Campinas. 